\title{
The whole and the parts: can lime coatings enhance the drying of salt laden materials?
}

Teresa Diaz Gonçalves*, Vânia Brito, Jessica Musacchi

National Laboratory for Civil Engineering (LNEC) - Department of Materials

Av. do Brasil 101, 1700-066 Lisbon, Portugal

* corresponding author: teresag@Inec.pt; tel: +351218443381

\begin{abstract}
Lime coatings are frequent in the architectural heritage. Previous research showed that they can accelerate the drying of porous materials, such as stone and mortars, which could help control the endemic problems of dampness of these constructions. Here, we investigate the effect lime coatings have in presence of soluble salts. The work is based on evaporation tests performed on one lime coating applied on five materials contaminated with solutions of $\mathrm{NaCl}$ or $\mathrm{Na}_{2} \mathrm{SO}_{4}$. Conclusions could be drawn about: (i) the behavior of the coating; (ii) the salt decay process. It was observed that the coating can, in few cases, still enhance drying when salts are present. However, in comparison to pure water, the drying kinetics is slower, more irregular and shows higher dispersion. Also, it sometimes diverges among specimens of the same material subjected to similar experimental conditions. These chaotic variations are in agreement with the decay patterns and suggest that soluble salts amplify the effects of the natural heterogeneity of porous materials.
\end{abstract}

Keywords: lime coating; limewash; architectural heritage; historical buildings; drying; porous building materials; soluble salts; sodium chloride; sodium sulphate 